\title{
Physicochemical Characterization of Geopolymer Binders and Foams Made from Tunisian Clay
}

\author{
Imen Ben Messaoud (D), ${ }^{1,2}$ Noureddine Hamdi, ${ }^{2,3}$ and Ezzeddine Srasra ${ }^{2}$ \\ ${ }^{1}$ Department of Materials, National School of Engineers of Sfax, 3038 Sfax, Tunisia \\ ${ }^{2}$ Laboratory of Composite Materials and Clay Minerals, National Center for Research in Materials Sciences (CNRSM), \\ 8020 Soliman, Tunisia \\ ${ }^{3}$ Higher Institute of Science and Techniques of Water of Gabès, University of Gabès, Zrig, 6072 Gabès, Tunisia \\ Correspondence should be addressed to Imen Ben Messaoud; imenbenmessaoud19@gmail.com
}

Received 28 August 2017; Accepted 11 December 2017; Published 4 February 2018

Academic Editor: Marino Lavorgna

Copyright (C) 2018 Imen Ben Messaoud et al. This is an open access article distributed under the Creative Commons Attribution License, which permits unrestricted use, distribution, and reproduction in any medium, provided the original work is properly cited.

\begin{abstract}
Illito-kaolinitic clay rich in hematite from south Tunisia was investigated in view of producing geopolymer materials. Geopolymers with two different densities were elaborated: cement and foam. The effects of activator concentrations on compressive strength, water absorption (durability), open porosity, and bulk density of geopolymers cement were examined, in order to assure optimal geopolymerization conditions. Geopolymer cements aged 28 days with optimum performances were achieved for $13 \mathrm{M}$ of alkaline solution concentration. At these conditions, the compressive strength of prepared geopolymer reaches $27.8 \mathrm{MPa}$. The addition of silica fume to reactant geopolymer mixture induces modification of geopolymer density and decrease in the compressive strength of the final product. Geopolymer materials based on calcined Tunisian clay can be suggested as sustainable and cost-effective cement that may be applied to alternate Portland cement in many construction applications.
\end{abstract}

\section{Introduction}

The demand of cement production continues to increase due to more population explosion. This material is used in almost every type of construction, including homes, buildings, roads, bridges, airports, and subways [1]. Unfortunately, total emissions from the cement industry could contribute as much as $8 \%$ of global $\mathrm{CO}_{2}$ emissions [2]. In the purpose of reducing the environmental construction impact, the aluminosilicate inorganic polymers, also called geopolymers present attractive alternative materials.

The preparation of geopolymer requires mixing simply reactive source of aluminosilicate with strong alkaline solutions and curing at temperatures $<100^{\circ} \mathrm{C}$ to get at an amorphous three-dimensional network.

Nevertheless, the geopolymerization process is still under study. The Gluhhovsky model divides the process into three stages: (i) destruction-coagulation; (ii) coagulationcondensation; (iii) condensation-crystallization [3]. Duxson et al. [3] have developed this theory in the purpose of better understanding of geopolymerization reaction. Thus, once mixed with the alkaline activated solution, the amorphous aluminosilicate powder is dissolved rapidly at high $\mathrm{pH}$ into free tetrahedral units of $\mathrm{SiO}_{4}$ and $\mathrm{AlO}_{4}$ [4]. These units are breaking up progressively with the reaction development. This quickly creates a supersaturated aluminosilicate solution. The oxygen atoms joined alternatively every two tetrahedral units, which leads to the formation of a gel in concentrated solutions. The oligomers in the aqueous phase form large networks by condensation. After gelation, the system continues to rearrange and reorganize, as the connectivity of the gel network increases, resulting in the threedimensional aluminosilicate network commonly attributed to geopolymers.

Geopolymers have variety of properties for the construction industry. For instance, geopolymers have good compressive strength resistance [5] allowing them to be an excellent alternative to Portland cement. Furthermore, 
geopolymers may find applications like thermal insulation or fireproof materials in foamed panels used as thermal insulation in the construction industry [6].

To obtain geopolymer foams (lightweight materials), different methods are possible, such as formation of foams with infiltration of a polymer perform [7] or use of a poreforming agent [8]. The final product depends directly on two factors, strictly speaking, the aluminosilicate source and the activator. Besides, the majority of geopolymer authors have examined different types of raw materials in order to produce geopolymer, for instance, metakaolin, fly ash, and blast furnace slag [9-11]. Metakaolin was made by controlled calcination. The process of thermal dehydroxylation breaks down the kaolin, for example, into metastable state (in terms of alumina environment) and quite disordered with the aim of improving their properties [12]. Indeed, the expulsion of $\mathrm{OH}^{-}$group from octahedral structure of kaolinite and the increase in disorder amplified the reactivity of metakaolin and promoted better characteristics of geopolymer products [13]. Moreover, a careful calcination may activate the material resulting in the rising of clay reactivity and improving the mechanical performance of the final product obtained [13]. In spite of that, firing to higher temperatures results in the formation of new unreactive phases such as mullite [12] that can influence the geopolymer characteristics. In this context, the range of calcinations temperature varies from one author to another. Nmiri et al. [14] reveal that the most convenient temperature to obtain the most reactive metakaolin is approximately $700^{\circ} \mathrm{C}$. Seiffarth et al. [15] studied the influence of the thermal pretreatment conditions on the reactivity of common clays alkaline earth solutions. Illite and illite-smectite clays were thermally activated between 550 and $950^{\circ} \mathrm{C}$ in oxidizing and reducing atmosphere, respectively. The mechanical properties of the geopolymeric binders can be improved by using clays calcined under reducing conditions [15]. Furthermore, according to Khater [16], the addition of silica fume up to $7 \%$ greatly enhances the geopolymerization process with the formation of a wellrefined and compact matrix.

Alkali-activating solution is also an important factor for the geopolymerization, especially at the level of the partially dissolution of reactive aluminosilicate source in highly alkaline media into $\mathrm{SiO}_{4}$ and $\mathrm{AlO}_{4}$ species [3]. For this precursor, the alkaline activators generally used are $\mathrm{NaOH}$ and $\mathrm{KOH}$. Potassium hydroxide should show a greater extent of dissolution due to its higher level of alkalinity. Nevertheless, reality demonstrates that it is $\mathrm{NaOH}$ that possesses a greater capacity to liberate silicate and aluminate monomers [17]. The amounts of dissolved units depend on alkali-activating solution type, concentration, and dissolution kinetics.

This paper aimed to investigate the elaboration of two types of geopolymeric materials (cement and foam) based on illito-kaolinitic clay. The specification of this clay is that it contains a significant proportion of hematite. The influence of this impurity on the final properties of the geopolymer samples will be investigated. The clay was first calcinated at different temperatures. Both calcinated and raw clay were investigated through XRD and Fourier transform infrared spectroscopy (FTIR). Geopolymer is considered as mostly an amorphous material, so all prepared geopolymer cements have been also analyzed by X-ray diffraction (XRD) and FTIR spectroscopy. The open porosity, water absorption, SEM, bulk density, and compressive strength of the hardened geopolymer cement pastes were also determined.

\section{Materials and Methods}

2.1. Material. Tunisian raw clay used in this study was originally extracted from Tejra site (Medenine) in the south of Tunisia. The chemical compositions of the starting materials are presented in Table 1. From these data, the relatively high $\mathrm{SiO}_{2}$ content is due to the presence of quartz phase in this clay and the red color can be attributed to the important percentage of $\mathrm{Fe}_{2} \mathrm{O}_{3}$.

The surface area $\left(S_{\mathrm{BET}}\right)$ and the pore volume $(\mathrm{Vp})$ of the raw clay are $39 \mathrm{~m}^{2} / \mathrm{g}$ and $0.116 \mathrm{~cm}^{3} / \mathrm{g}$, respectively. Dried clay fraction was crushed and sieved to $75 \mu \mathrm{m}$. According to particle size distributions (Figure 1) obtained after grinding, there are two populations with a distribution: the first with a maximum at around $1 \mu \mathrm{m}$ and the second with a maximum of about $40 \mu \mathrm{m}$. This shows that the size of this sample is very small but strongly agglomerated [18]. The raw material was then calcined in a programmable electric furnace (Nabertherm) at a constant rate of $10^{\circ} \mathrm{C} / \mathrm{min}$ for 2 hours.

The alkaline activator solution was obtained by dissolving $\mathrm{NaOH}$ pellets in sodium silicate solution. The commercial sodium hydroxide $(\mathrm{NaOH})$ with $99.2 \%$ purity and the sodium silicate $\left(\mathrm{Na}_{2} \mathrm{SiO}_{3}\right)$ powder supplied from Fisher company with a density of $2.4 \mathrm{~g} \cdot \mathrm{cm}^{-3}$ and a molar ratio $\mathrm{SiO}_{2} / \mathrm{Na}_{2} \mathrm{O}$ of 2 . The activator solutions were prepared 24 hours prior to use.

2.2. Sample Preparations. Table 2 presents details of the mix proportions of this study. For the purpose of elaborating geopolymer materials, the clay was pretreated at $950^{\circ} \mathrm{C}$ for 2 hours and activated by sodium activator.

The hydroxide pellets and the sodium silicate powder are firstly dissolved in distilled water and cooled down to room temperature. Thermally treated clay powder was slowly added into the alkaline solution for geopolymer cement, whereas $8 \%$ of silica fume was added with calcined clay in order to prepare geopolymer foam. The mixture was stirred for 5 minutes with a mechanical agitator. Then, the fresh geopolymeric paste is rapidly placed into plastic cylindrical moulds with a diameter $(\varnothing)$ of $16 \mathrm{~mm}$ and a height $(h)$ of $32 \mathrm{~mm}$. The samples were vibrated for few minutes on the vibration table to remove entrained air. In order to prevent the evaporation of mixing water and the surface carbonation, the geopolymer cement samples were covered by plastic film during the hardening process and left to cure under ambient temperature (approximately $22^{\circ} \mathrm{C}$ ). The mold is removed after hardening of the specimens. At the end of the curing regime, after 28 days, the samples were dried well at $60^{\circ} \mathrm{C}$ for $24 \mathrm{~h}$ in order to complete the geopolymerization [19] and then exposed to compressive strength measurements. Fresh geopolymer foams were then placed in an oven at $70^{\circ} \mathrm{C}$ to constant weight. 
TABLE 1: Chemical composition of the raw material (wt.\%).

\begin{tabular}{lcccccccc}
\hline Compounds & $\mathrm{SiO}_{2}$ & $\mathrm{Al}_{2} \mathrm{O}_{3}$ & $\mathrm{Fe}_{2} \mathrm{O}_{3}$ & $\mathrm{MgO}$ & $\mathrm{CaO}$ & $\mathrm{Na}_{2} \mathrm{O}$ & $\mathrm{K}_{2} \mathrm{O}$ & $\mathrm{LOI}$ \\
\hline Clay & 55.14 & 14.22 & 8.12 & 3.65 & 1.76 & 0.53 & 2.73 & 13.11 \\
\hline
\end{tabular}

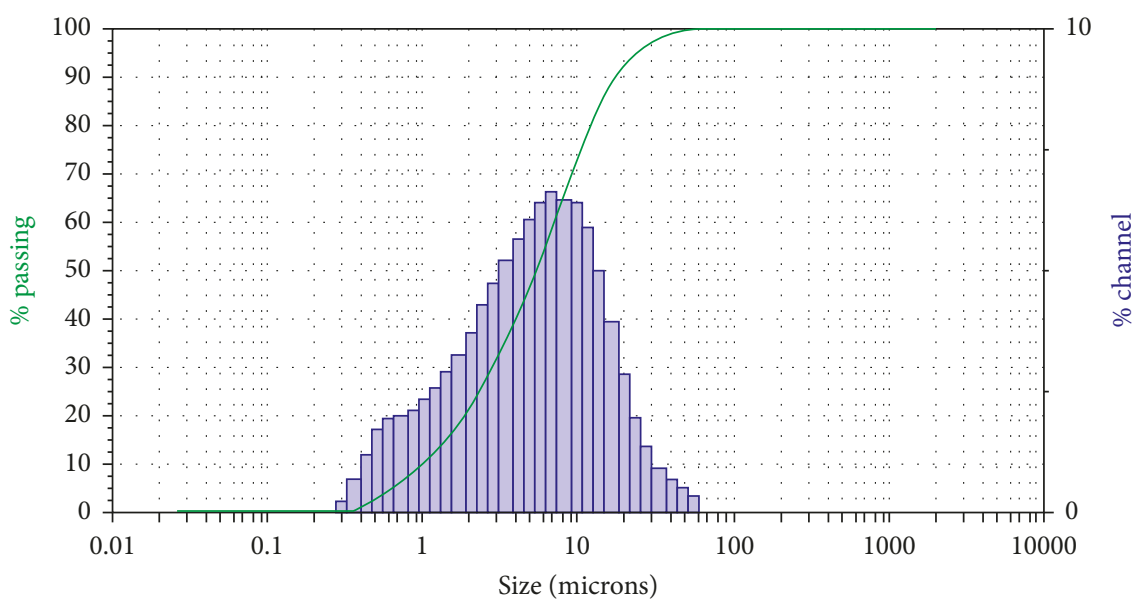

Figure 1: Particle size distribution of raw clay.

TABle 2: Preview of the experimental runs.

\begin{tabular}{lcccccc}
\hline \multirow{2}{*}{ Mix } & \multicolumn{2}{c}{ Factors } & \multicolumn{2}{c}{ Activators (g) } & \multicolumn{2}{c}{ Solvent (distilled water) (g) } \\
& Heated temperature $\left({ }^{\circ} \mathrm{C}\right)$ & $\mathrm{NaOH}$ concentration $(\mathrm{mol} / \mathrm{l})$ & & $\mathrm{Na}_{2} \mathrm{SiO}_{3}$ & $\mathrm{NaOH}$ & 4 \\
M1 & 950 & 8 & 10 & 0.06 & 0.96 & 4 \\
M2 & 950 & 13 & 10 & 0.06 & 1.56 & 4 \\
M3 & 950 & 15 & 10 & 0.06 & 1.18 & 4 \\
M4 & 950 & 18 & 10 & 0.06 & 2.16 & 4 \\
M5 $^{*}$ & 950 & 8 & 9.2 & 0.06 & 0.96 & 4 \\
\hline
\end{tabular}

${ }^{*}$ Eight percent of the clay was replaced by silica fume supplied from Sika $\left(95.0 \mathrm{wt} . \%\right.$ silica and $1.3 \mathrm{wt} . \%$ carbon, $\left.S_{\mathrm{BET}}=23 \mathrm{~m}^{2} / \mathrm{g}\right)$.

2.3. Methods. Chemical composition was determined by ICP-AES. Loss on ignition (LOI) was established as the difference of the weight percent between samples heated at 100 and $1000^{\circ} \mathrm{C}$.

Mineralogical analysis of the raw sample, calcinated clays and geopolymer samples was carried out by X-ray diffraction. The analyses were recorded on Phillips X' Pert diffractometer spectrometer. The XRD patterns obtained by a scanning rate of $1^{\circ}$ per min from $2 \theta=4^{\circ}$ to $80^{\circ}$ and steps of $2 \theta=0.04^{\circ}$.

The open porosity, bulk density, and water absorption were measured according to ASTM C2000.

IR analysis has been carried out using a Nicolet spectrophotometer model 560 spectrophotometer. Fourier transform infrared spectroscopy absorption spectra were recorded in the $4000-400 \mathrm{~cm}^{-1}$ range using a Nicolet system, equipped with a DTGS KBr (deuterated triglycine sulphate with potassium bromide windows) detector. $\mathrm{KBr}$ pellets were prepared by mixing 5 wt.\% of geopolymer cement or raw and calcined clay powder with 95 wt.\% $\mathrm{KBr}$ and then pressing.

Compressive strengths of the hardened geopolymer cement were tested using a LLOYD EZ50 universal testing machine with a crosshead speed of $3 \mathrm{~mm} / \mathrm{min}$. The surfaces of the hardened geopolymer cement sample were flat, parallel, and polished to avoid requirements for capping.

The samples were tested after 28 days and all the values presented in the current work were an average of samples for each cure temperature. Each sample was repeated three times.

Apparent porosities, water absorptions, and bulk densities were carried out using Archimedes' method, also known as boiling water method. After putting them in distilled water, the samples were boiled for $2 \mathrm{~h}$ for the investigation [20]. Each sample was repeated three times.

BET method using a Quantachrome Autosorb instrument was applied to determinate the specific surface area, and the pore volume of raw clay was determined from nitrogen adsorption isotherm at $77 \mathrm{~K}$. Selected samples were also used for the scanning electron microscopy (SEM) with the aim to analyze morphological features of porous geopolymer.

\section{Results and Discussion}

3.1. Characterization of Clay Fractions. Few studies have been carried out on the suitability of illito-kaolinitic 
Tunisian clays on the synthesis of geopolymer samples. In particular, illito-kaolinitic clay has shown appropriate properties for building ceramic [12]. Thus, the suitability of different clays in different applications is strongly dependent on its mineralogical and chemical composition. Iron can affect the thermal behavior and phase formation during heat treatment and consequently influence the final mechanical properties of the building ceramic [21]. For that reason, the chemical and mineralogical composition and the thermal behavior need to be considered before suitable clay qualities can be selected for geopolymer as an application. Table 1 represents the results of chemical composition of the clay fractions. The $\mathrm{SiO}_{2} / \mathrm{Al}_{2} \mathrm{O}_{3}$ ratio is different from 1 . This result indicates that the clay sample is not pure clay (or kaolinite pure). The high iron levels $\left(8 \%\right.$ of $\left.\mathrm{Fe}_{2} \mathrm{O}_{3}\right)$ justify the red color of the investigated clay.

The mineralogical composition of the raw and calcined clay samples is reported in Figure 2. X-ray diffraction pattern shows the presence of quartz (ICCD 01-085-1780), kaolinite (ICCD 01-089-6538), hematite (ICCD 01-087-1164), dolomite (ICCD 01-075-1760), and illite (ICCD 00-002-0050), as principal mineralogical phases for raw clay.

The clay samples were then calcined at 550, 750, 850, 950, and $1050^{\circ} \mathrm{C}$ for $2 \mathrm{~h}$ and analyzed by $\mathrm{X}$-ray diffraction (Figure 2 ). It is found that the reflections of kaolinite disappeared after increasing the temperature up to $550^{\circ} \mathrm{C}$ and transformed into amorphous state of metakaolin, indicating its destruction in (001) direction [22]. Concerning the illite reflections, no significant changes were detected at this temperature, because of its higher thermal stability [23].

However, at $950^{\circ} \mathrm{C}$, illite is no longer detected in the $\mathrm{X}$-ray diffractograms. This is suggested to be due to the collapse of the illite structure with the increase in the heating temperature [12]. Above this calcination temperature, especially at $1050^{\circ} \mathrm{C}$, quartz and hematite are the only existing crystalline phases in clay.

The comparison between raw clay sample and the calcined clay sample at $550,750,850,950$, and $1050^{\circ} \mathrm{C}$ shows several changes detected through FTIR spectra in Figure 3.

The broadband at about $3427 \mathrm{~cm}^{-1}$ and $1635 \mathrm{~cm}^{-1}$ shows adsorbed atmospheric water $[24,25]$. The absorption band at $3612 \mathrm{~cm}^{-1}$ and a shoulder band at $3695 \mathrm{~cm}^{-1}$ are assigned to stretching vibrations of octahedral $\mathrm{OH}$ bonds attached to the $\mathrm{Al}$ octahedron sheet. With the rise of temperature, these bands disappear, indicating dehydroxylation of the clay. In addition, the band relative to $\mathrm{Si}-\mathrm{O}$ stretching vibrations was presented in IR spectrum at $477 \mathrm{~cm}^{-1}$ [26].

The Si-O-Si asymmetric vibration at $1030 \mathrm{~cm}^{-1}$ is also present in the IR spectrum [24]. The quartz (high content in this sample) is identified at 780 and $796 \mathrm{~cm}^{-1}$ in infrared spectroscopy [24].

The band centered at $1030 \mathrm{~cm}^{-1}$ in the IR spectrum becomes broad due to decreasing crystalline kaolinite structure during calcination and formation of metakaolin. Characteristic peak of Si-O-Al bending vibration was presented in the IR spectrum at $536 \mathrm{~cm}^{-1}$ and disappears at $950^{\circ} \mathrm{C}$ [27].

According to these results and for the purpose of preparing reactive clay for the geopolymer synthesis, the clay will be used as calcined at $950^{\circ} \mathrm{C}$ for 2 hours.
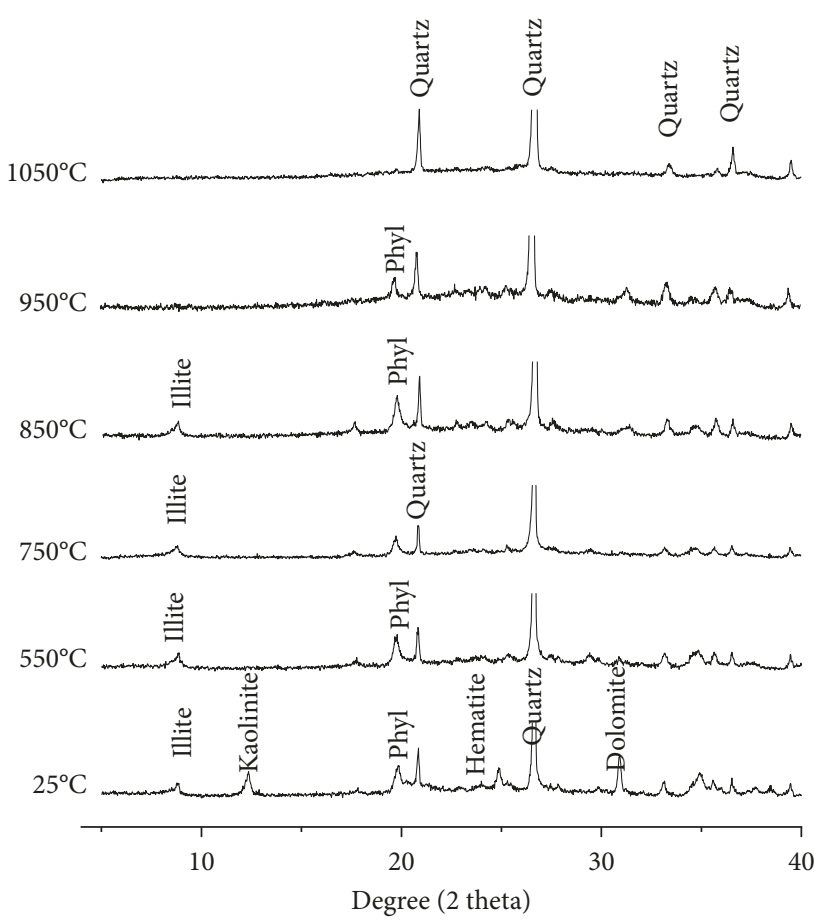

FIGURE 2: XRD patterns of Tunisian clay samples and thermally calcined samples. Phyl $=$ phyllosilicate.

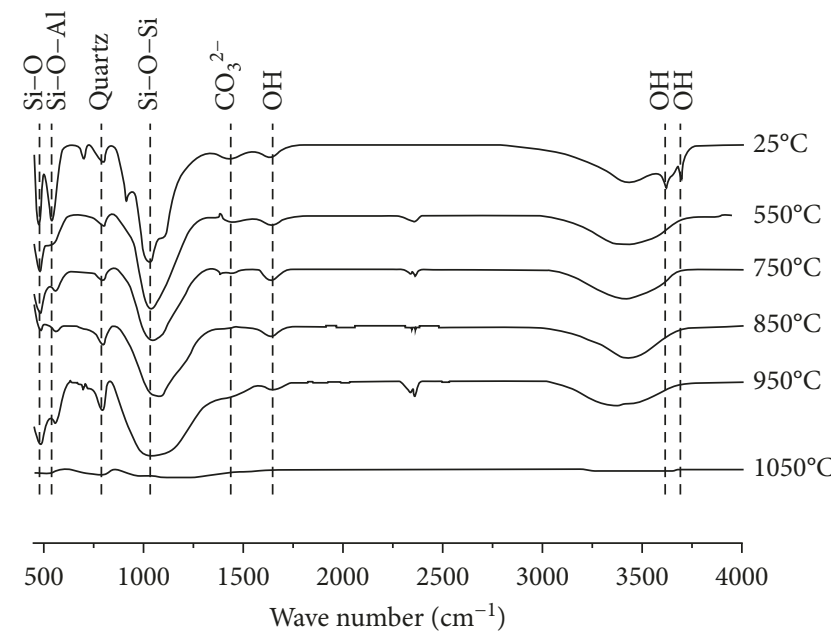

FIGURE 3: Fourier transform infrared (FTIR) spectra of raw and calcined clay.

3.2. Optimization of Geopolymer Cement Mixture. Concentration of alkali activator is an important factor that affects the microstructural development of the systems as well as the $\mathrm{Si} / \mathrm{Al}$ ratio, and hence directly the final products $[3,28]$. In fact, strong alkalis are required during the first step of the process in order to dissolve the silica and alumina from raw materials.

To examine the role of the alkaline solution on the compressive strength of hardened geopolymer cement pastes and according to the previous results, the temperature 


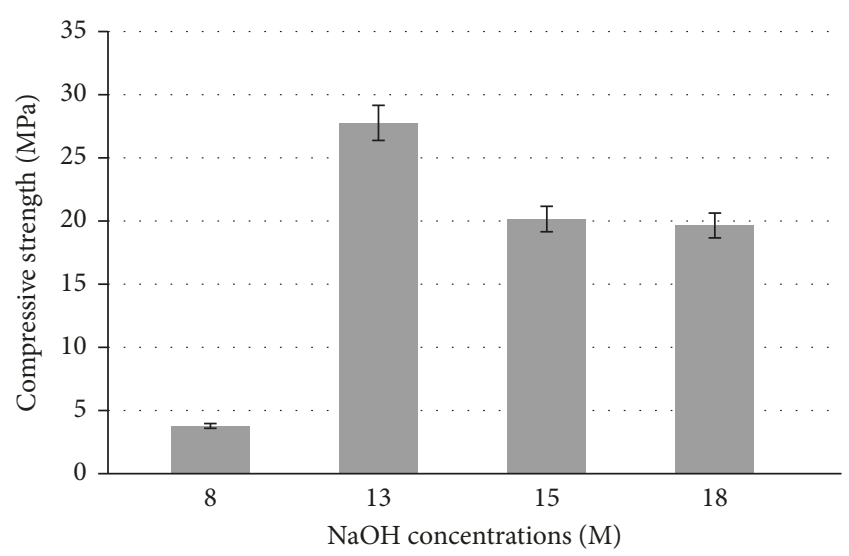

FIGURE 4: Compressive strengths of hardened geopolymer cement prepared with various $\mathrm{NaOH}$ concentrations.

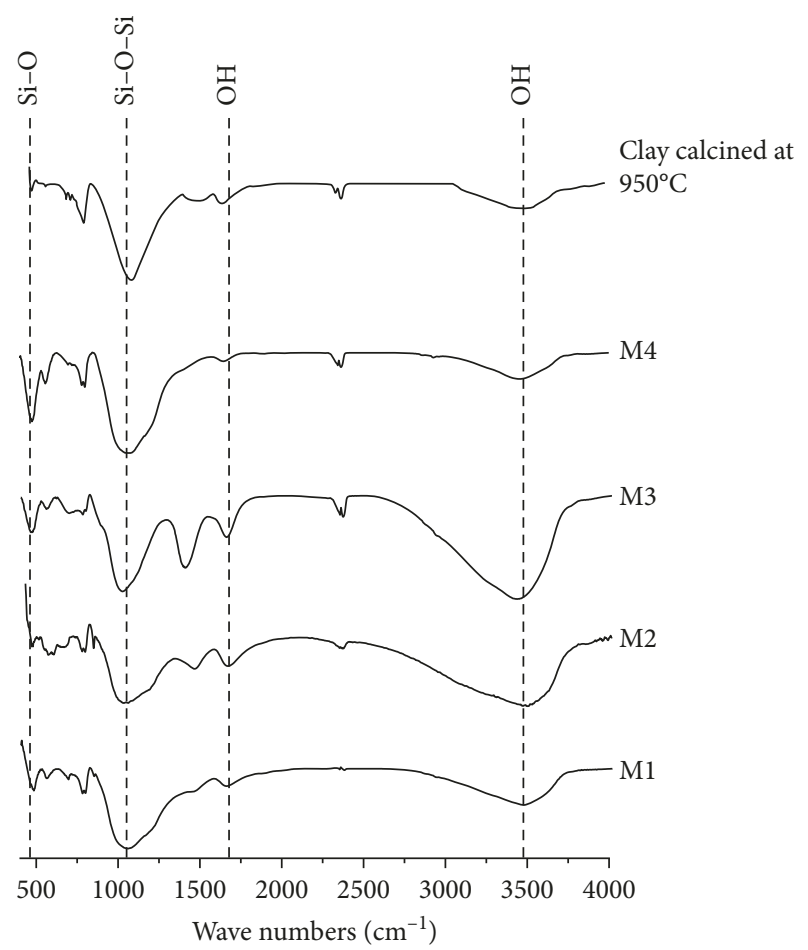

FIGURE 5: Fourier transform infrared (FTIR) spectra of the geopolymer cement prepared with various $\mathrm{NaOH}$ concentrations.

of calcinations was fixed at $950^{\circ} \mathrm{C}$ and four different $\mathrm{NaOH}$ concentrations were supplied, as mentioned in Table 2.

The compressive strengths of hardened geopolymer cements prepared with various $\mathrm{NaOH}$ concentrations are presented in Figure 4.

Geopolymer samples made with $8 \mathrm{M} \mathrm{NaOH}$ (M1) have the lower compressive strength after 28 days of curing. An increase in the $\mathrm{NaOH}$ concentration from 8 to $13 \mathrm{M}$ (M2) causes an increase in the compressive strength of the final geopolymers. But, when the concentration of $\mathrm{NaOH}$ exceeds $13 \mathrm{M}$ exactly for M3 and M4, the compressive strength declined. This result tendency is surprising, because the compressive strength was normally expected

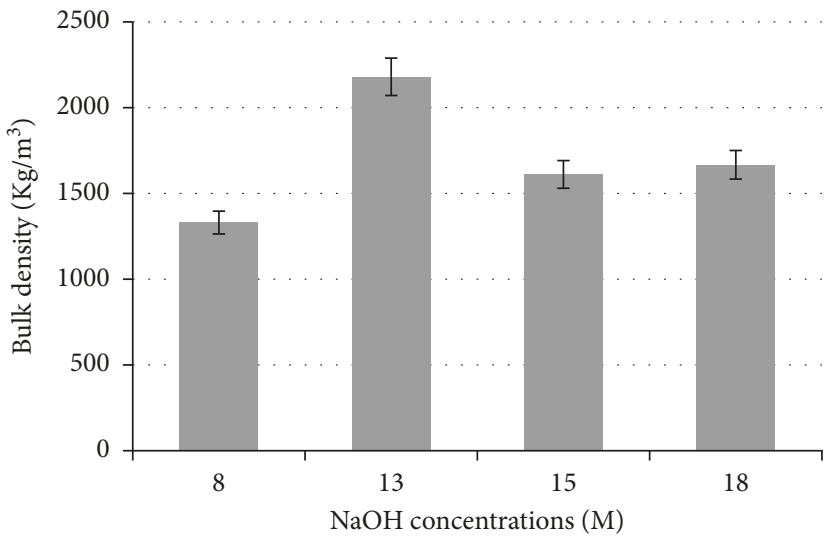

FIGURE 6: Bulk density of geopolymer cement prepared with various $\mathrm{NaOH}$ concentrations.

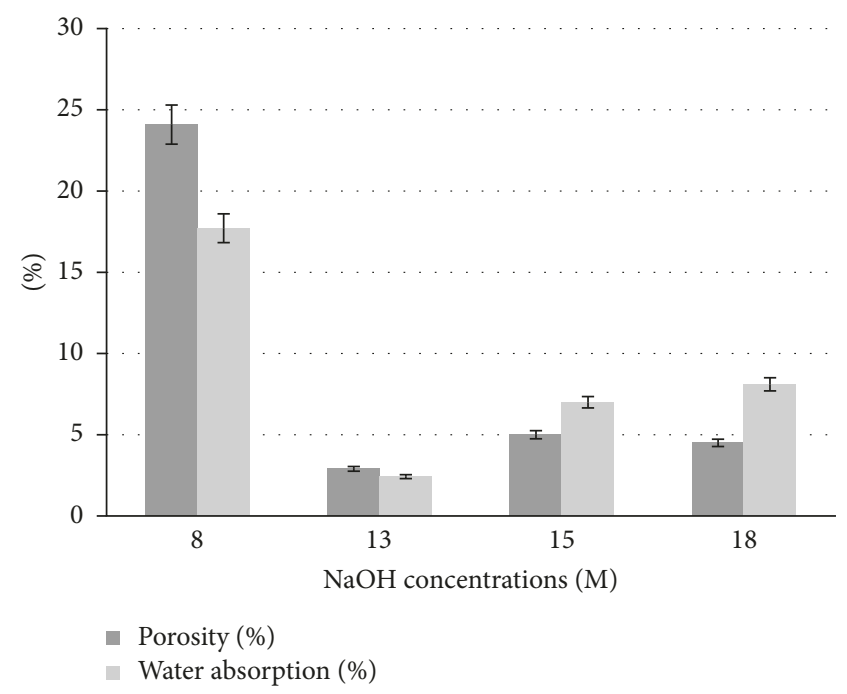

FIgURE 7: Open porosity and water absorption of geopolymer cement prepared with various $\mathrm{NaOH}$ concentrations.

to increase with increasing $\mathrm{NaOH}$ concentrations. Nevertheless, these results may be related with two factors which are the dissolution/hydrolysis of alumina and silica and polycondensation to form geopolymer. The reasons for this attitude can be explained by the excess hydroxide ion concentration when higher $\mathrm{NaOH}$ concentration solutions were used. In fact, this excess caused the precipitation of the aluminosilicate gel at a very early stage. As a consequence, geopolymerization was precluded which lead to lower strength geopolymers [29]. From these results, the geopolymer samples activated with $13 \mathrm{M} \mathrm{NaOH}$ had the optimum alkaline environment and the best compressive strength values when comparing with other geopolymer samples prepared using different concentrations of $\mathrm{NaOH}$. Furthermore, Essaidi et al. have investigated the role of hematite in aluminosilicate gels based on metakaolin [30]. They found that the presence of iron oxide in the clay fraction does not contribute in the formation of geopolymer materials. The particles of hematite not altered by the geopolymerization 


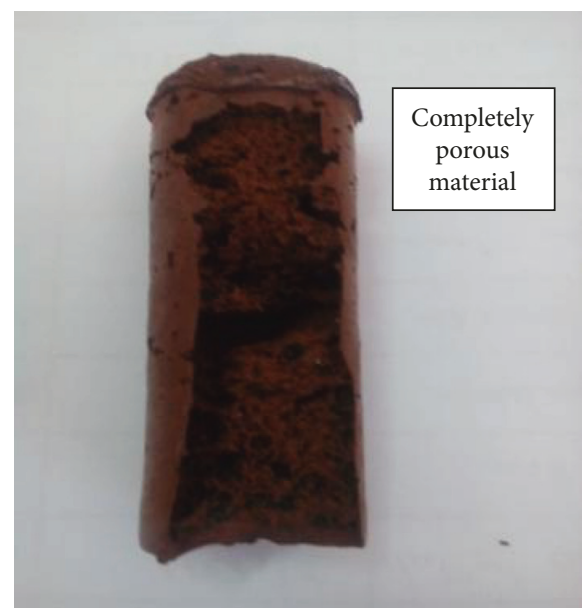

(a)

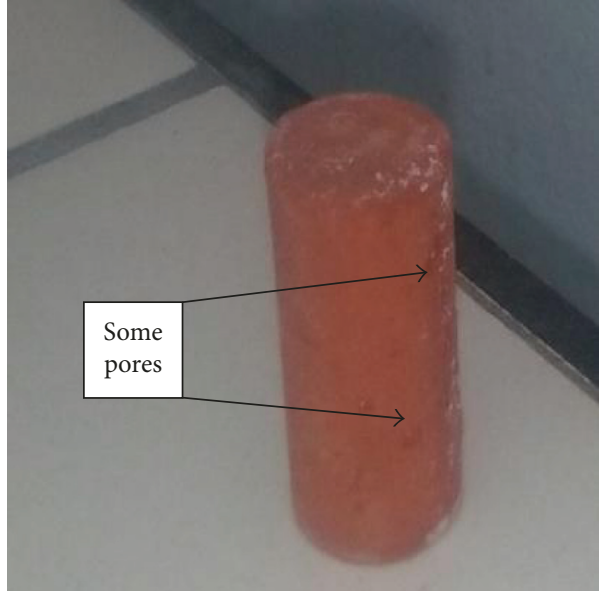

(b)

Figure 8: Photographs of obtained geopolymer foam (a) and geopolymer cement (b).

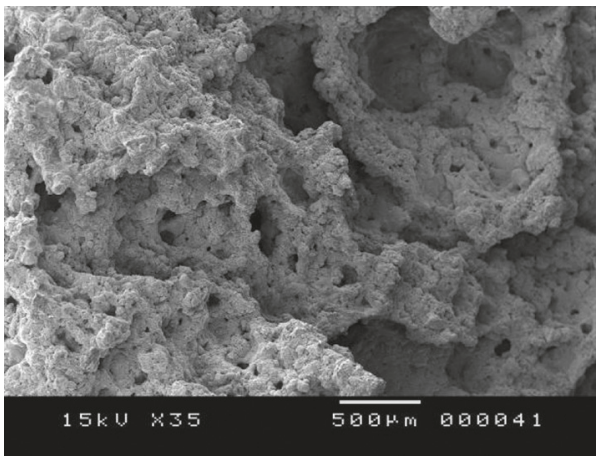

(a)

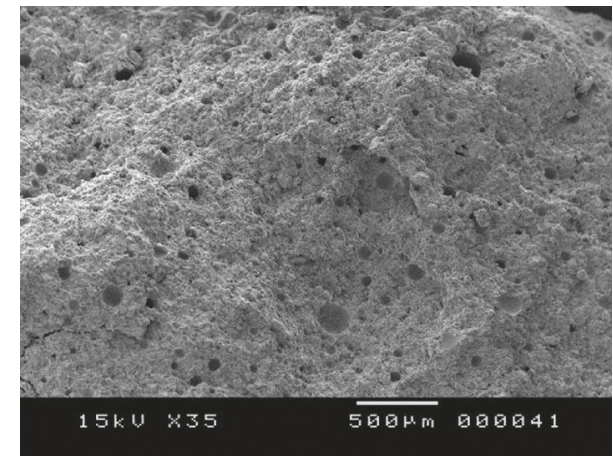

(b)

FIGURE 9: SEM pictures of (a) geopolymer foam M5 and (b) geopolymer cement M2.

reaction lead to the formation of different specific networks other than geopolymer network that act as a reinforcing load and cause the improvement of mechanical properties [30].

Figure 5 presents the FTIR spectra of calcined clay at $950^{\circ} \mathrm{C}$ powders and the cured geopolymer samples prepared with various $\mathrm{NaOH}$ concentrations. A broad band was detected at the wave number of $3442 \mathrm{~cm}^{-1}$ corresponding to $\mathrm{O}-\mathrm{H}$ stretching and the hydroxyl group present in the water molecule. A significant broad band centered at the wave number of $1070 \mathrm{~cm}^{-1}\left(1032 \mathrm{~cm}^{-1}\right.$ for unheated clay) for the calcined clay corresponds to Si-O-Si asymmetric stretching. This very particularly area is a proof of changing $\mathrm{Al}$ substitution in the tetrahedral sites of silica framework. For all geopolymer mixture samples, this band was shifted to lower wave number which point to chemical modification in the geopolymer matrix followed by the formation of new products resulting from the mix of the clay and the alkaline solution. For the mixture M2, the bands were significantly decreased in intensity. This modification in intensity shows the amorphous phase in the depolymerized clay to $\mathrm{Si}-\mathrm{O}$ and $\mathrm{Al}-\mathrm{O}$ bonds, whereas the displacement suggests the polycondensation of these bonds in the alkaline environment.
With the increase of $\mathrm{NaOH}$ concentrations, the activation of calcined clay was improved which further increased the $\mathrm{Al}$ substitution in $\mathrm{Si}-\mathrm{O}-\mathrm{Si}$ bond, that is why the broad bands were shifted to lower wave number. The $\mathrm{Si}-\mathrm{O}-\mathrm{Si}$ band of quartz identified at 780 and $796 \mathrm{~cm}^{-1}$ does not contribute in the geopolymerization process. The absorption band around $1450 \mathrm{~cm}^{-1}$ in the FTIR spectra of M3 is related to stretching vibrations of $\mathrm{C}-\mathrm{O}$ sodium carbonate bond which leads to efflorescence.

Concerning the density of the hardened geopolymer cement pastes (Figure 6), it is clear that the evolution of bulk density has the same shape of the compressive strength results. In other words, $13 \mathrm{M} \mathrm{NaOH}$ gains the highest value of the density $2179.8 \mathrm{~kg} / \mathrm{m}^{3}$. While for open porosity and water absorption (Figure 7), the results were inversed. The lowest open porosity and water absorption levels favored by $13 \mathrm{M} \mathrm{NaOH}$ achieved best mechanical performance, confirming the effect that the porosity is unfavorable for the mechanical performance.

3.3. Characterization of Geopolymer Materials. The addition of silica fume to the reactant geopolymer mixture induces 


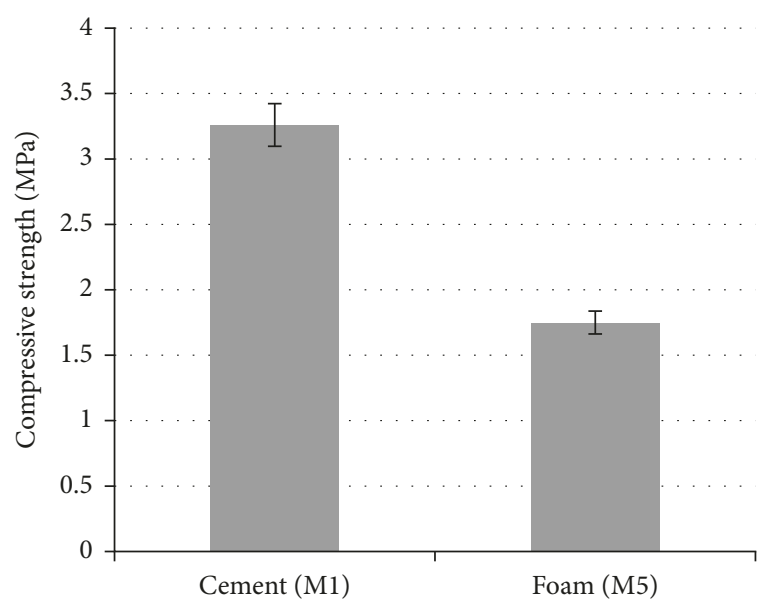

FIGURE 10: Compressive strength of geopolymer materials activated with $8 \mathrm{M}$ of $\mathrm{NaOH}$.

the expansion of the sample volume and creates a multiscale porosity [8] as presented in Figure 8.

The visual observation of the geopolymer materials activated by $8 \mathrm{M}$ of $\mathrm{NaOH}$ reveals difference between the two synthesized materials where geopolymer cement presents mainly compact consolidated materials with some cavity resulted from the entrained air during molding. However, geopolymer foam presents $49 \%$ of porosity.

SEM pictures of the geopolymer samples presented in Figure 9 confirm that the microstructure of geopolymer cement was relatively compact compared to geopolymer foam. This porosity is mostly the cause of the decrease in the compressive strength of the geopolymer foam aged of 28 days (Figure 10) [31].

According to these results, geopolymer foams can be used for thermal insulation applications [32].

\section{Conclusion}

The analysis of raw Tunisian clay, namely, chemical analyses, FTIR, and XRD revealed the presence of illite and kaolinite phases in the clay fraction associated with quartz, hematite, and dolomite.

Despite the relatively high hematite content in the clay, the optimization of geopolymer cement synthesis was successfully achieved with a compressive strength comparable to cement Portland ( $30 \mathrm{MPa})$. For the concentration effect, there is a minimum value for the porosity and water absorption and a maximum for the density at $13 \mathrm{M}$. The optimum compressive strength of hardened geopolymer was $27 \mathrm{MPa}$.

The introduction of silica fume to the geopolymer mixture creates $49 \%$ of porosity inside the samples and decreases the mechanical performances.

\section{Conflicts of Interest}

The authors declare that there are no conflicts of interest regarding the publication of this paper.

\section{References}

[1] F. Gouny, F. Fouchal, O. Pop, P. Maillard, and S. Rossignol, "Mechanical behavior of an assembly of wood-geopolymerearth bricks," Construction and Building Materials, vol. 38, pp. 110-118, 2013.

[2] R. M. Andrew, "Global $\mathrm{CO}_{2}$ emissions from cement production," Earth System Science Data Discussions, vol. 77, pp. 1-52, 2017.

[3] P. Duxson, A. Fernández-Jiménez, J. L. Provis, G. C. Lukey, A. Palomo, and J. S. J. Van Deventer, "Geopolymer technology: the current state of the art," Journal of Materials Science, vol. 42, no. 9, pp. 2917-2933, 2007.

[4] M. B. Ogundiran and S. Kumar, "Synthesis and characterisation of geopolymer from Nigerian Clay," Applied Clay Science, vol. 108, pp. 173-181, 2015.

[5] K. Al-Zboon, M. S. Al-Harahsheh, and F. B. Hani, "Fly ashbased geopolymer for $\mathrm{Pb}$ removal from aqueous solution," Journal of Hazardous Materials, vol. 188, no. 1-3, pp. 414-421, 2011.

[6] M. Łach, K. Korniejenko, and J. Mikuła, "Thermal insulation and thermally resistant materials made of geopolymer foams," Procedia Engineering, vol. 151, pp. 410-416, 2016.

[7] L. Montanaro, Y. Jorand, G. Fantozzi, and A. Negro, "Ceramic foams by powder processing," Journal of the European Ceramic Society, vol. 18, no. 9, pp. 1339-1350, 1998.

[8] E. Prud'homme, P. Michaud, E. Joussein, C. Peyratout, A. Smith, and S. Rossignol, "In situ inorganic foams prepared from various clays at low temperature," Applied Clay Science, vol. 51, no. 1-2, pp. 15-22, 2011.

[9] F. Pelisser, E. L. Guerrino, M. Menger, M. D. Michel, and J. A. Labrincha, "Micromechanical characterization of metakaolin-based geopolymers," Construction and Building Materials, vol. 49, pp. 547-553, 2013.

[10] P. Sukmak, S. Horpibulsuk, and S.-L. Shen, "Strength development in clay-fly ash geopolymer," Construction and Building Materials, vol. 40, pp. 566-574, 2013.

[11] W. K. W. Lee and J. S. J. Van Deventer, "The effects of inorganic salt contamination on the strength and durability of geopolymers," Colloids and Surfaces A: Physicochemical and Engineering Aspects, vol. 211, no. 2-3, pp. 115-126, 2002.

[12] E. Escalera, R. Tegman, M. L. Antti, and M. Odén, "High temperature phase evolution of Bolivian kaolinitic-illitic clays heated to $1250^{\circ} \mathrm{C}$," Applied Clay Science, vol. 101, pp. 100-105, 2014.

[13] a. Elimbi, H. K. Tchakoute, and D. Njopwouo, "Effects of calcination temperature of kaolinite clays on the properties of geopolymer cements," Construction and Building Materials, vol. 25, no. 6, pp. 2805-2812, 2011.

[14] A. Nmiri, N. Hamdi, M. Duc, and E. Srasra, "Synthesis and characterization of kaolinite-based geopolymer: alkaline activation effect on calcined kaolinitic clay at different temperatures," Journal of Materials and Environmental Sciences, vol. 8, no. 2, pp. 276-290, 2017.

[15] T. Seiffarth, M. Hohmann, K. Posern, and C. Kaps, "Effect of thermal pre-treatment conditions of common clays on the performance of clay-based geopolymeric binders," Applied Clay Science, vol. 73, no. 1, pp. 35-41, 2013.

[16] H. M. Khater, "Effect of silica fume on the characterization of the geopolymer materials," International Journal of Advanced Structural Engineering, vol. 5, no. 1, pp. 1-12, 2013.

[17] P. Duxson, J. L. Provis, G. C. Lukey, S. W. Mallicoat, W. M. Kriven, and J. S. J. Van Deventer, "Understanding the relationship between geopolymer composition, 
microstructure and mechanical properties," Colloids and Surfaces A: Physicochemical and Engineering Aspects, vol. 269, no. 1-3, pp. 47-58, 2005.

[18] I. Hedfi, N. Hamdi, E. Srasra, and M. A. Rodríguez, "The preparation of micro-porous membrane from a Tunisian kaolin," Applied Clay Science, vol. 101, pp. 574-578, 2014.

[19] M. S. Muñiz-Villarreal, A. Manzano-Ramírez, S. SampieriBulbarela et al., "The effect of temperature on the geopolymerization process of a metakaolin-based geopolymer," Materials Letters, vol. 65, no. 6, pp. 995-998, 2011.

[20] T. W. Cheng and J. P. Chiu, "Fire-resistant geopolymer produced by granulated blast furnace slag," Minerals Engineering, vol. 16, no. 3, pp. 205-210, 2003.

[21] A. Aras, "The change of phase composition in kaolinite- and illite-rich clay-based ceramic bodies," Applied Clay Science, vol. 24, no. 3-4, pp. 257-269, 2004.

[22] M. A. Soleimani, R. Naghizadeh, A. R. Mirhabibi, and F. Golestanifard, "Effect of calcination temperature of the kaolin and molar $\mathrm{Na}_{2} \mathrm{O} / \mathrm{SiO}_{2}$ activator ratio on physical and microstructural properties of metakaolin based geopolymers," Iranian Journal of Materials Science and Engineering, vol. 9, no. 4, pp. 43-51, 2012.

[23] C. Ferone, B. Liguori, I. Capasso et al., "Thermally treated clay sediments as geopolymer source material," Applied Clay Science, vol. 107, pp. 195-204, 2015.

[24] M. Mezni, a. Hamzaoui, N. Hamdi, and E. Srasra, "Synthesis of zeolites from the low-grade Tunisian natural illite by two different methods," Applied Clay Science, vol. 52, no. 3, pp. 209-218, 2011.

[25] R. A. Alvarez-Puebla, D. S. Dos Santos, C. Blanco, J. C. Echeverria, and J. J. Garrido, "Particle and surface characterization of a natural illite and study of its copper retention," Journal of Colloid and Interface Science, vol. 285, no. 1, pp. 41-49, 2005.

[26] J. L. Rendon, "IR spectra of powder hematite: effects of particle size and shape," Clay Minerals, vol. 16, no. 4, pp. 375-382, 1981.

[27] E. Srasra, F. Bergaya, and J. J. Fripiat, "Infrared spectroscopy study of tetrahedral and octahedral substitutions in an interstratified illite-smectite clay," Clays and Clay Minerals, vol. 42, no. 3, pp. 237-241, 1994.

[28] S. a. Bernal, J. L. Provis, V. Rose, and R. Mejía De Gutierrez, "Evolution of binder structure in sodium silicate-activated slag-metakaolin blends," Cement and Concrete Composites, vol. 33, no. 1, pp. 46-54, 2011.

[29] K. Somna, C. Jaturapitakkul, P. Kajitvichyanukul, and P. Chindaprasirt, "NaOH-activated ground fly ash geopolymer cured at ambient temperature," Fuel, vol. 90, no. 6, pp. 2118-2124, 2011.

[30] N. Essaidi, B. Samet, S. Baklouti, and S. Rossignol, "The role of hematite in aluminosilicate gels based on metakaolin," Ceramics-Silikáty, vol. 58, no. 1, pp. 1-11, 2014.

[31] J. G. Sanjayan, A. Nazari, L. Chen, and G. H. Nguyen, "Physical and mechanical properties of lightweight aerated geopolymer," Construction and Building Materials, vol. 79, pp. 236-244, 2015.

[32] J. Henon, A. Alzina, J. Absi, D. S. Smith, and S. Rossignol, "Potassium geopolymer foams made with silica fume pore forming agent for thermal insulation," Journal of Porous Materials, vol. 20, no. 1, pp. 37-46, 2013. 


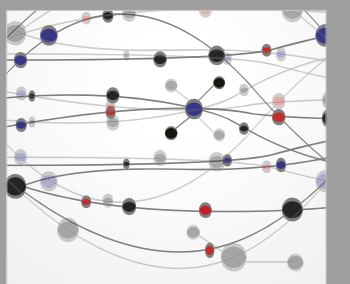

The Scientific World Journal
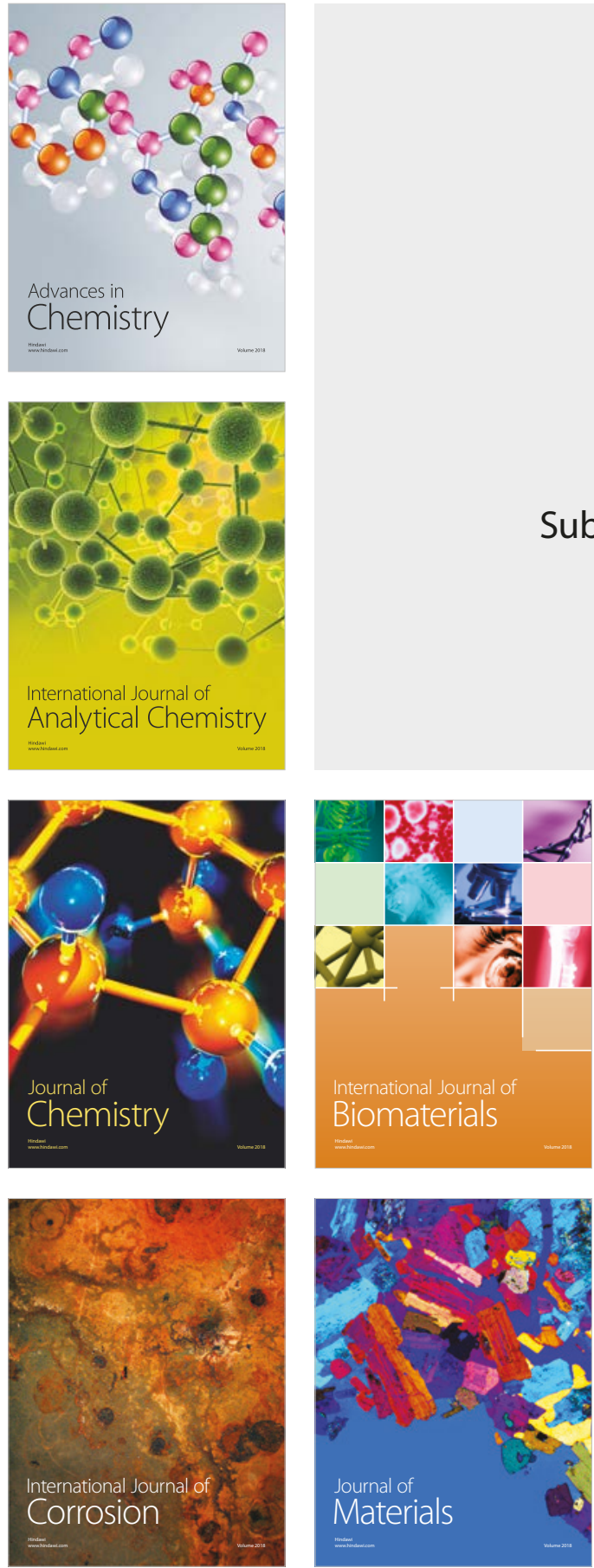

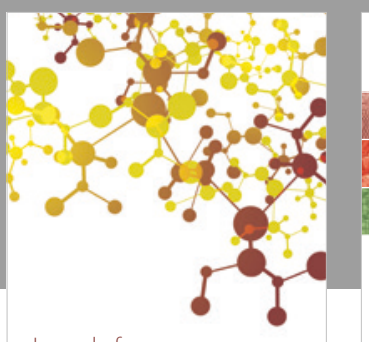

Journal of

Applied Chemistry
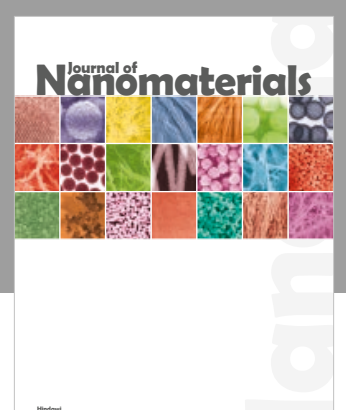

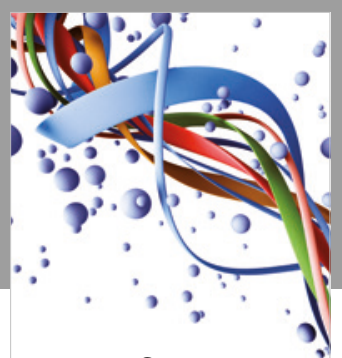

Scientifica

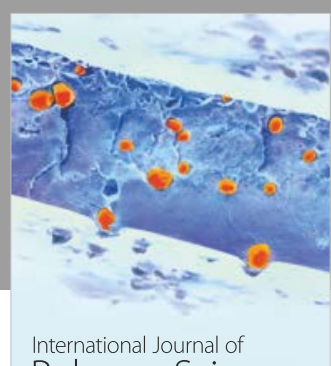

Polymer Science

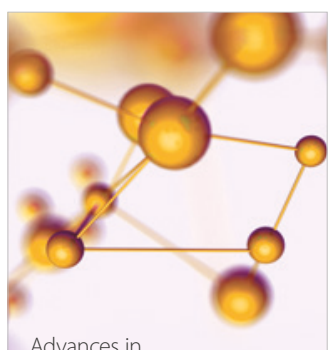

Physical Chemistry
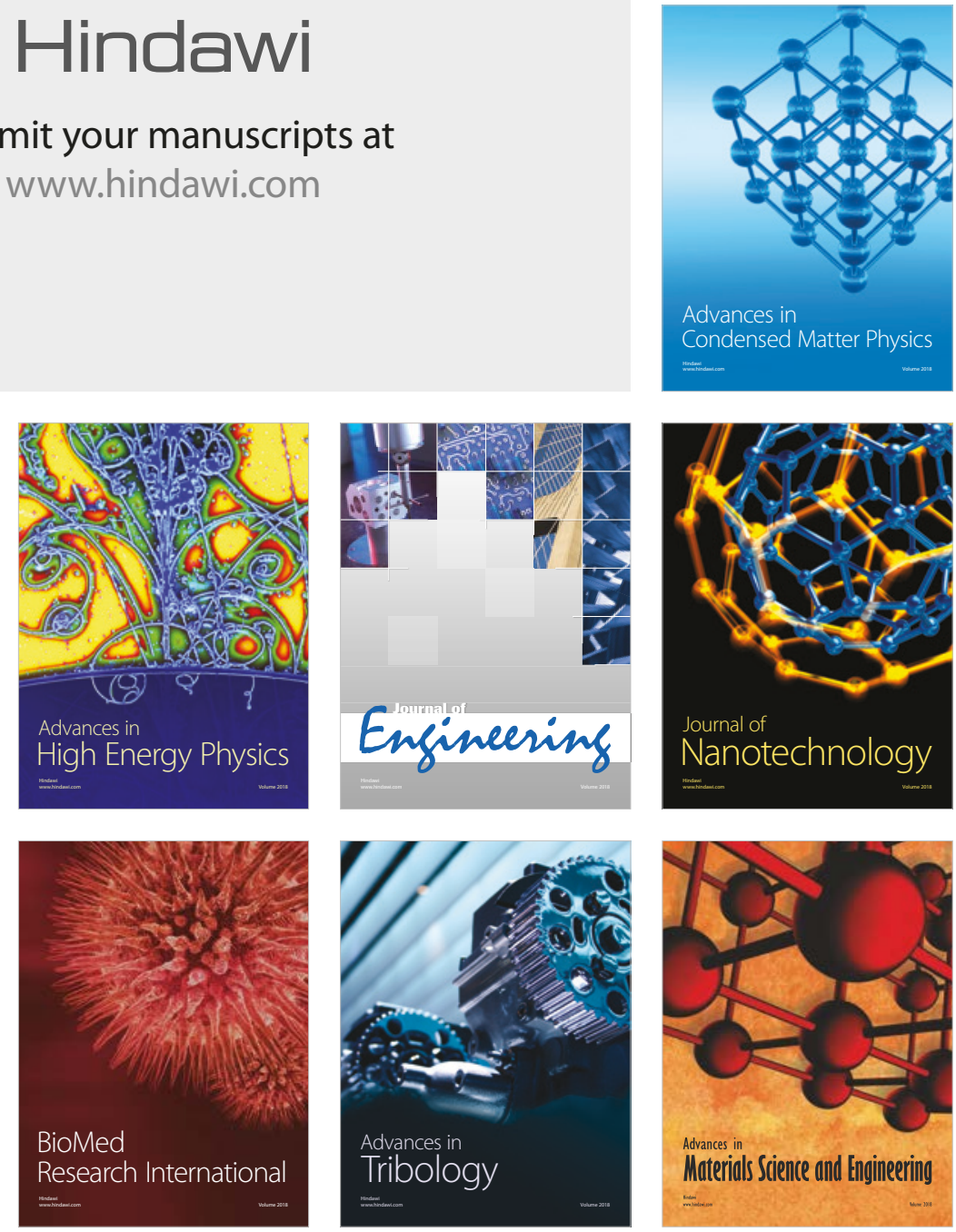